Article

\title{
An Examination of the Mental Health and Negative Life Events of Women Who Killed Their Children
}

\author{
Margarita Poteyeva ${ }^{1, *}$ and Margaret Leigey ${ }^{2}$ \\ 1 Department of Justice Studies, James Madison University, Harrisonburg, VA 22807, USA \\ 2 Department of Criminology, The College of New Jersey, Ewing Township, NJ 08618, USA; leigeym@tcnj.edu \\ * Correspondence: poteyemx@jmu.edu; Tel.: +1-540-568-7124
}

Received: 22 July 2018; Accepted: 17 September 2018; Published: 19 September 2018

\begin{abstract}
Research on filicide, the killing of a child by a biological or a de facto parent or parents, has largely focused on mothers. However, little is known about how filicidal women compare to filicidal men or whether they differ from women who commit non-filicide murder. The study explores pre-incarceration negative life events and mental health histories of women incarcerated for filicide as compared to men incarcerated for the same offense and women who were incarcerated for non-filicide murder. Extensive gender differences in filicidal parents were found in terms of economic marginalization, physical and sexual abuse, mental health problems. Filicidal women had more mental health problems and lower monthly income than women incarcerated for non-filicide murder, but there were more similarities than differences detected between the two groups of female offenders. The paper concludes with policy recommendations.
\end{abstract}

Keywords: filicide; women offenders; family violence; homicide

\section{Introduction}

Filicide, the killing of a child by a biological or a de facto parent or parents, is a rare but disturbing occurrence. According to data from the United States, filicides comprise about 3\% of all reported homicides (Dixon et al. 2014; Weekes-Shackelford and Shackelford 2004). Both mothers and fathers commit filicide, but the gender distribution varies depending on the type. Mothers are overrepresented in cases of the murder of younger children-neonaticide, a murder of a child in the first $24 \mathrm{~h}$ after birth, and infanticide, a murder of a child between one day old and one year old (Bourget et al. 2007). A recent American study analyzing 32 years of arrest data found that women comprised $51.2 \%$ of offenders who killed infants and $44.4 \%$ of offenders who killed victims between the ages of 1-17 (Mariano et al. 2014).

Violent crimes, and especially murder, are rarely perpetrated by women (Fox and Fridel 2017). As such, when women commit murder, "they attract more media and public attention, the image created of them is more powerful, and they leave a more long-lasting impression" (Jewkes 2015, p. 134). Filicide is unique in that the rate of female perpetrators is higher in comparison to the proportion of women committing other forms of homicide (Putkonen et al. 2016). Research on maternal filicide is characterized by small, unrepresentative, clinical samples. There are very few large-scale studies and often they examine a fairly narrow range of offender, victim and offense characteristics (Dixon et al. 2014; Weekes-Shackelford and Shackelford 2004). Furthermore, few studies of maternal filicide analyze data from the United States (Crimmins et al. 1997; Oberman and Meyer 2008), the bulk of filicide research are based on European data.

Filicide is a heterogeneous phenomenon. We adopt the perpetrator-based definition of filicide, which is based on the victim-offender relationship and not on the circumstances surrounding the child's death (Sidebotham 2013). We do not differentiate between intentional homicide of children, 
extreme neglect or maltreatment deaths, and incidents of fatal physical abuse. All of these violent and maltreatment-related deaths are considered filicide if perpetrated by victim's biological or de facto parent or parents.

The current study examines the pre-incarceration negative life events and the mental health histories of 55 women incarcerated in the United States for killing their child or stepchild. These filicidal mothers are compared to two reference groups: (1) men incarcerated for filicide (filicidal men); and (2) women who were incarcerated for killing someone other than their child or stepchild (non-filicidal women).

The study fills several gaps in existing research. First, very little is known about the childhood experiences of women who kill their children. With few exceptions, research has not systematically assessed various childhood difficulties and potential sources of trauma among filicidal women, such as residing in public housing or growing up with a parent who struggles with substance abuse. Furthermore, the current study includes previously unexplored indicators of economic marginalization. While previous research has largely focused on prevalence of unemployment, low education and public assistance, no identified study has examined prevalence of homelessness and income levels of filicidal women.

Second, there is a lack of research comparing maternal versus paternal filicide, as studies typically focus on either maternal or paternal filicide and rarely comparing the two (Dixon et al. 2014). Consequently, there is no research consensus on such matters as the prevalence of physical abuse in the lives of filicidal men and women, and on whether there are any gender differences in economic hardship indicators. Additionally, our study delves deeper than many others in comparing mental health histories of filicidal men and women. We examine prior suicide attempts, mental health hospital stays, and distribution of specific diagnoses, variables rarely addressed in existing studies, which typically focus on mere prevalence rates of mental health issues.

Finally, virtually nothing is known about how women who kill their children compare to women who commit other types of homicide. Do filicidal women represent a unique category of violent female offenders? Recent studies from Northern Europe suggest an answer in the affirmative as they have found that filicide perpetrators are distinctive from other homicide offenders (Lysell et al. 2014; Putkonen et al. 2009), but they have not disaggregated filicide perpetrators by gender.

\section{Literature Review}

\subsection{Research on Childhood Negative Life Events of Filicidal Women}

Research exploring the lives of filicidal women depicts a childhood replete with various difficulties. Some have grown up in poverty, and many have witnessed inter-parental violence and were raised by neglectful or abusive parents who struggled with substance abuse or cycled in and out of prison. Oberman and Meyer (2008), drawing on interviews with 37 women who were convicted of murder and involuntary manslaughter for killing their child, concluded that many of them had a childhood "full of isolation" where "[love] came with a price tag" (p. 6).

Rates of childhood abuse and neglect of filicidal women vary across studies, most likely because of different operationalization of the phenomenon. For example, "childhood abuse" was indicated in case files of $63 \%$ of 68 Finnish mothers who killed or attempted to kill their child (Haapsalo and Petaja 1999). In Wilczynski (1997) British study of 65 filicide cases, $43.8 \%$ of women suffered a broadly conceived "maltreatment or disruption of their childhood" (p. 97), but only $12.5 \%$ reported having been physically abused. A study of 42 incarcerated women who were convicted of murder or manslaughter in New York revealed that 19\% were seriously physically abused during childhood (Crimmins et al. 1997). Lastly, in a review of forensic case files of 20 women charged with murdering their children, Mckee and Shea (1998) found that none of the women reported being a victim of child neglect, $15 \%$ reported being physically abused, and 35\% reported being sexually abused. 
Beyond filicidal women's experiences of childhood abuse and neglect, very little is known about other aspects of their childhood family life. The limited research available suggests that their early lives were marked with family conflict and violence, poverty, and parental substance abuse. For example, $40 \%$ of women in an Eriksson et al. study (Eriksson et al. 2016) reported exposure to parental violence. Mckee and Shea (1998) found that $80 \%$ reported their primary family income having been in the lower third of socioeconomic status. Crimmins et al. (1997) found that more than a third of the sample had alcoholic mothers and $29 \%$ had an alcoholic (step)father. However, whether filicidal women were more likely to experience childhood trauma than the reference groups is unknown.

Some studies have suggested a potential link between childhood trauma and filicide (Debowska et al. 2015; Mugavin 2005; Oberman and Meyer 2008; Smithey 1997). For instance, Crimmins et al. (1997) have approached the issue from a self-psychological perspective, suggesting that serious negative experiences during childhood cause damage to a woman's self, making it difficult for her to care for dependents. Additionally, struggles during childhood might make it harder for a woman to rely on others later in life, and social isolation and lack of social supports have been widely acknowledged as risk factors for filicide (Alder and Polk 2001; D'Orban 1979; Oberman and Meyer 2008; Wilczynski 1997). Other studies have suggested that exposure to violence socializes girls to some degree that predisposes them to violent outbursts as mothers (Mugavin 2005; Smithey 1997). Finally, inability to manage with childhood trauma might lead to various negative coping mechanisms including alcohol and drug abuse (Edalati and Krank 2016), which in turn have been recognized as contributing factors in filicide research (Hatters Friedman and Resnick 2007).

\subsection{Negative Life Events during Adulthood of Filicidal Women}

Abuse is an all too common reality for incarcerated women (Leigey and Reed 2010), including those incarcerated for filicide. Having interviewed 37 women incarcerated at the Ohio Reformatory for Women, Oberman and Meyer (2008) note that violence is "endemic to these women's lives" (p. 5), it is common during childhood and persists into adulthood. Many women in their sample sustained violent victimization at the hands of their intimate partners, family members, friends but also strangers. While other studies agree with Oberman and Meyer (2008) finding, there is no uniform consensus on the exact prevalence of violence. About $60 \%$ of women in Wilczynski's British study (1997) report experiencing domestic violence. Putkonen et al. (2011), analyzing all cases of filicide that have occurred in Finland and Austria between 1995-2005, found that 17\% of women report being physically abused and $7 \%$ report being sexually abused as an adult. In the United Kingdom and Canada, 21\% of Mckee and Shea (1998) sample reported adult physical abuse. The same proportion of women in Crimmins et al. (1997) study report having an abusive partner. This American study found a very high prevalence of adult victimization- $71 \%$ of women reported serious physical harm and $31 \%$ reported experiencing serious sexual harm. The differences in estimates of violence most likely are explained by different operationalizations of the concept and by different reference periods (e.g., lifetime prevalence versus a more limited time period).

Studies that attempt to explain the phenomenon of filicide have drawn attention to socio-economic disadvantages plaguing the lives of perpetrators. Limited education, unemployment, poverty, and housing insecurity have been identified as risk factors in the literature (Alder and Polk 2001; Beyer et al. 2008; Harris et al. 2007; Hatters Friedman and Resnick 2007; Leveillee et al. 2007; Scott and Fleming 2014; Smithey 1997; Wilczynski 1997). Between a third to a half of filicidal women have not graduated high school (Crimmins et al. 1997; Eriksson et al. 2016; Putkonen et al. 2011). Spinelli (2003) reports that women who drop out of high school are eight times more likely to murder their infant than women who had a college education, even when age is controlled. A lack of educational resources begets a lack of financial affluence. Subsequently, a common finding is a high prevalence of unemployment among female perpetrators of filicide; across several studies, only $25 \%$ to $40 \%$ of filicidal mothers report paid employment (Flynn et al. 2013; Putkonen et al. 2011; 
Wilczynski 1997). A sizable proportion, between $30 \%$ to $40 \%$ of women, cite welfare or being on public assistance as their source of income (Crimmins et al. 1997; Wilczynski 1997).

Economic marginalization is especially problematic as it means that women are limited in accessing mental health care. This not only increases feelings of stress and anxiety but has implications for how women feel about themselves, about their worth, and about the future. Studies of filicidal women document their feelings of powerlessness, hopelessness, and lack of support prior to the offense (Alder and Polk 2001; D'Orban 1979; Oberman and Meyer 2008; Wilczynski 1997). No previous studies of filicidal women have examined the two indicators of economic marginalization included in the current study: monthly income and homelessness.

\subsection{Research on Mental Health Histories of Filicidal Women}

Mental health histories and psychiatric characteristics of female filicide offenders have garnered a lot of research attention. However, the findings on the matter have not been conclusive. Studies debate the prevalence of mental disorders, the distribution of specific psychiatric diagnoses, and their relative contribution to the offense. As with the other equivocal findings, one potential reason for inconsistent findings is the varying study designs. Studies that include in their sample a high proportion of neonaticides note a lower prevalence of mental health problems (Bourget and Gagne 2002; D'Orban 1979; Hatters Friedman et al. 2005; Lewis and Bunce 2003). Alternatively, studies that include cases of filicide-suicide, where a parent takes his or her life after killing their child, tend to find a higher rate of mental disorders (Kauppi et al. 2010). For example, in one study, of the $40 \%$ of mothers who committed suicide after the offense, $85 \%$ had mental health problems (Bourget and Gagne 2002).

Another reason for disparate findings is the nature of sample populations used in the studies, most commonly psychiatric, registers or medical files and corrections. Some studies have examined offenders found in psychiatric or forensic facilities, transferred there for treatment in lieu of a custodial sentence or awaiting a pretrial psychiatric evaluation (e.g., Krischer et al. 2007; Liem and Koenraadt 2008; Lewis and Bunce 2003). Since these studies are based on biased samples, they expectedly find a high prevalence of psychotic and other mental disorders. For example, more than half of 82 women who killed or attempted to kill their children and were held under observation in a forensic psychiatric hospital in the Netherlands were mentally ill at the time of filicide (Liem and Koenraadt 2008). A review of the files of 55 filicidal women evaluated at the Center for Forensic Psychiatry in Michigan revealed that half $(48 \%)$ were diagnosed with schizophrenia and a third (35\%) were diagnosed with major depressive disorder with psychotic features (Lewis and Bunce 2003).

Studies that obtain their samples from national registers (e.g., Flynn et al. 2013; Sidebotham and Retzer 2018; Wilczynski 1997) or rely on medical examiners' / coroners' files (e.g., Bourget and Gagne 2002; Leveillee et al. 2007) that examine every filicide that occurred in a specific region over a certain period of time are better representative of the general population of filicide offenders. Even still, their findings on the role that mental health plays in filicide is mixed. Flynn et al. (2013) analyzed a sample of filicide and filicide-suicide case in England and Wales from 1997 to2006. Out of 102 mothers, over a third were mentally ill at the time of the offense and a fifth had previously been in contact with mental health services. In the majority of cases, mental illness was not present. However, some studies in this category find a much higher prevalence of mental health problems (Bourget and Gagne 2002; Hatters Friedman et al. 2005; Wilczynski 1997).

A third group of studies have relied on correctional populations, and consequently cited lower rates of mental illness (e.g., Crimmins et al. 1997; Oberman and Meyer 2008). In these studies, given the selection bias that inherently exists, fewer women were diagnosed with a mental illness. This is because offenders with serious mental disorders might not have been tried for their crimes because they were evaluated as not competent to stand trial, or they might have been adjudicated not guilty by reason of insanity. Finally, if convicted, they might be confined in mental institutions rather than prisons.

In media accounts of maternal filicide, the perpetrator is oftentimes portrayed as insane (Barnett 2006). Contrary to this stereotype, psychosis-related child homicide is actually quite rare 
(Flynn et al. 2013; Hatters Friedman et al. 2005), yet the proportion of those suffering from psychosis is higher among female filicide perpetrators than in the general population ( $0.5 \%$ for women) (Flynn et al. 2013). Women who kill their children are actually more likely to suffer from schizophrenia and affective disorders such as major depression and psychotic depression rather than from psychosis (Flynn et al. 2013; Krischer et al. 2007).

\subsection{Comparing Filicidal Mothers to Filicidal Fathers}

There is a growing body of research comparing filicidal mothers to their male counterparts, and a number of well-established gender differences in offense characteristics have emerged. First, victims of maternal filicide tend to be younger than victims of paternal filicide (Kauppi et al. 2010; Putkonen et al. 2011; Vanamo et al. 2001; Wilczynski 1997). This finding is consistent with research that has noted women are disproportionately more likely to commit infanticide (Hatters Friedman and Resnick 2007; Porter and Gavin 2010). Second, female child homicide offenders, especially mothers, have been reported to rarely use weapons, but instead rely on other means such as drowning, suffocation, and the use of so-called personal weapons (e.g., hands and feet), whereas male offenders display an inclination to use knives, guns and blunt objects to inflict lethal violence (Alder and Polk 2001; Kauppi et al. 2010; Liem and Koenraadt 2008; Mariano et al. 2014).

Third, filicidal mothers and fathers differ considerably in terms of underlying motivational factors (Alder and Polk 2001; Harris et al. 2007; Liem and Koenraadt 2008; Wilczynski 1997; Wilson et al. 1995). Women are more likely to kill while being affected by mental illness, or if a child is unwanted, or to commit so-called altruistic filicide, where the killing is perceived by the offender to be in the child's best interest. Motive categories that are disproportionately characteristic of men include retaliatory killings, where the anger towards another person is displaced onto a child, or escalating physical abuse.

Fourth, filicidal women have a less extensive criminal history than men (Eriksson et al. 2016; Lysell et al. 2014; Putkonen et al. 2011; Sidebotham and Retzer 2018; Wilczynski 1997). Finally, several studies have noted a markedly different perception and legal treatment of men and women who killed their children (Amon et al. 2018; Flynn et al., 2013; Wilczynski, 1997). Women are treated more leniently; they are less likely than men to be prosecuted, less likely to be convicted of murder, receive shorter sentences, and are more likely to receive a psychiatric disposal rather than a custodial sentence. According to Wilczynski (1997), "men are [perceived as] bad and normal, women are mad and abnormal" (p. 422).

The areas that are the focus of the current study, mental illness and negative life events, have received less research attention, and findings oftentimes have been conflicting. For example, with childhood and adult victimization, while some studies (Krischer et al. 2007; Putkonen et al. 2011) note more childhood victimization among women, a recent Australian study (Eriksson et al. 2016) found that a significantly higher proportion of men reported childhood incidence of physical abuse and neglect, emotional neglect and exposure to parental violence. Equally scarce is research on adult victimization. Putkonen et al. (2011) examining data from Austria and Finland found that 17\% of female perpetrators of filicide report being physically abused as an adult versus just 3\% of men. Wilczynski (1997) found that the proportion of women who report domestic violence was over three times greater than men (60\% versus $18 \%)$.

Turning to economic marginalization, very few studies have explored gender differences, and, when they have, the findings are conflicting. Two studies have found that a similar proportion of men and women report being unemployed (Flynn et al. 2013; Putkonen et al. 2011). In the Flynn et al. (2013) study, about $60 \%$ of filicidal mothers and fathers report being unemployed. In contrast, Wilczynski (1997) finds that, while a higher proportion of women in her sample were unemployed, men were more likely to report experiencing financial difficulties. In this study, women were also a bit more educated than men, while two recent studies from Northern Europe found no statistically significant differences in terms of education (Lysell et al. 2014; Putkonen et al. 2011). To the best of our knowledge, no studies have examined gender differences in income or homelessness. 
With regards to mental illness, most studies find that the prevalence of mental illness is higher among filicidal women than filicidal men (Bourget et al. 2007; Eriksson et al. 2016; Flynn et al. 2013; Kauppi et al. 2010; Resnick 1969; Sidebotham and Retzer 2018; Wilczynski 1997), though exceptions exist (Benitez-Borrego et al. 2013). However, there is less agreement across studies in regards to the size of the gender gap in mental health issues. Some studies revealed that two times as many filicidal mothers suffer from mental health disorders as compared to fathers (Flynn et al. 2013; Wilczynski 1997), while others note that the gender difference in prevalence is less pronounced (Kauppi et al. 2010; Liem and Koenraadt 2008). Findings about the distribution of particular diagnoses are also not consistent, specifically about the prevalence of depression among filicidal parents. While some studies revealed that depression is much more prevalent among filicidal women than men (Flynn et al. 2013; Kauppi et al. 2010; Leveillee et al. 2007), others found no significant gender differences for depression (Liem and Koenraadt 2008; Lysell et al. 2014).

Suicide is an under-researched dimension of mental health in the filicidal literature. As noted above, filicide-suicide is one form of filicide. Estimates of filicide-suicide range across studies from $16 \%$ to $65 \%$ of all filicides (Lysell et al. 2014). Although men are much more likely than women to commit filicide-suicide (Alder and Polk 2001; Flynn et al. 2013; Hatters Friedman et al. 2005; Putkonen et al. 2011), very little is known about gender differences in suicide attempts among filicide offenders more generally, taking place before the offense. In a Swedish study of 151 filicide offenders, men and women had an approximately equal number of prior suicide attempts, $13.4 \%$ and $14.5 \%$, respectively (Lysell et al. 2014).

\subsection{Comparing Filicidal Mothers to Other Female Homicide Perpetrators}

How filicidal women compare to other women who commit murder is another major gap in the homicide literature. Several studies have compared offense characteristics, psychosocial history and forensic psychiatric characteristics of filicide offenders to other homicide perpetrators without disaggregating the groups by gender (Lysell et al. 2014; Putkonen et al. 2009; Wilbanks 1983). This body of research has produced conflicting findings. For example, a recent study relying on data from Finland did not find that filicide offenders had significantly more mental illness and more serious psychopathology than the control group (Putkonen et al. 2009), but a recent Swedish study reached the opposite conclusion (Lysell et al. 2014).

We were able to locate only three studies that have examined the differences between filicidal women and other female homicide perpetrators. McKee and Shea (1996) compared 30 women charged with killing their own child to women charged with killing either their partner or an unrelated adult. They found that the three groups of women did differ on a number of demographic, historical, clinical, and offense characteristics. Compared to the other two groups, filicidal women had a higher prevalence of a severe mental illness diagnosis and were less likely to have a prior criminal record or to have been intoxicated during the alleged offense. Furthermore, very few of these women had the social or emotional resources necessary for coping with extreme stress. In an extension of this project, the authors compared the three groups' scores on the Minnesota Multiphasic Personality Inventory-2 (MMPI-2) clinical and content scales (McKee et al. 2001) and found no significant differences between the groups.

Finally, a recent descriptive study drawing data from the Australian Homicide Project, compared 14 filicidal parents with 217 male and female non-filicide perpetrators in terms of background, criminal history, and childhood and adulthood adversities (Eriksson et al. 2016). Compared to women who have perpetrated other forms of homicide, filicidal women had a lower prevalence of childhood adversities (e.g., physical and emotional abuse and neglect or exposure to parental violence), were less likely to be employed, were less likely to have sustained severe intimate partner violence, did not experience substantial alcohol or drug problems, and had less serious criminal histories. A higher proportion of filicidal women, however, have received treatment or assessment for mental health 
issues ( $40 \%$ compared to $27.3 \%$ of non-filicidal women). Unfortunately, there were only five filicidal mothers in this study, so further research employing larger samples is warranted.

\section{Methodology}

Anonymized data, relevant to this study's research questions, were extracted and merged from the 1997 and 2004 versions of the Survey of Inmates in State and Federal Facilities, a national level dataset. Data were collected for the Bureau of Justice Statistics $(1997,2004)$ and made available to the public via the Interuniversity Consortium for Political and Social Research. A two-stage sample design was employed, whereby state and federal institutions were first selected and then subjects were selected from sampled institutions. Prior to the in-person interview, respondents were informed that their participation was voluntary and their responses would be kept confidential. Interviews lasted approximately an hour in length.

From the combined 1997 and 2004 data, a total of 416 cases were obtained: 55 women $(1997=29$; $2004=26)$ and 28 men $(1997=17 ; 2004=11)$ who were incarcerated for either the murder or the manslaughter of their biological child or stepchild and 333 women $(1997=206 ; 2004=127)$ who were imprisoned for either the murder or the manslaughter of someone else. Respondents were carefully screened by the research team to ensure that each was unique and no respondent was included twice in the merged dataset.

Study measures focused on the pre-incarceration negative life events and mental health histories for the female filicide group. The negative life events examined in this study spanned the life course. Respondents in the present study were asked to report if, at any point in their childhoods, they were placed in foster care (foster care), resided in public housing (public housing), received public assistance (public assistance as child), or if their caretakers had an issue with substance abuse, including drugs or alcohol (caretaker substance abuse). They were also asked to indicate if a parent had ever been incarcerated (parental incarceration).

Abuse and economic deprivation were also explored. Respondents were asked if prior to incarceration they had ever been a victim of sexual abuse (sexual abuse) or physical abuse (physical abuse). Economic deprivation measures included in the analysis were whether respondents had been homeless in the year prior to arrest (homeless), and if, in the month prior to arrest, they received any public assistance, such as welfare (public assistance in the month prior to arrest), if they were employed (employed), or if they reported a low monthly income (monthly income). With the exception of monthly income, all of these measures were dummy-coded, with 1 indicating a response of yes and 0 a response of no. A13-category monthly income measure was included in the analysis.

The other group of measures pertained to the mental health of respondents. Respondents in both the 1997 and 2004 surveys were asked if they had ever taken a medication (medication), received counseling (counseling), or stayed overnight in a hospital or other facility (hospital stay) for a mental/emotional problem. In the 2004 version of the survey, additional mental health items were included. Specifically, respondents were asked if they had ever attempted suicide (suicide attempt) and if they had ever been diagnosed with a depressive disorder (depressive disorder), bipolar disorder (bipolar disorder), schizophrenia (schizophrenia), post-traumatic stress disorder (PTSD), anxiety disorder (anxiety disorder), personality disorder (personality disorder), or some other mental/emotional problem (other mental/emotional problem). In addition to examining the prevalence of these particular mental health disorders, they were collapsed into a single measure of mental/emotional problem, an item included in the 1997 version. All of these measures were dummy-coded, with 1 indicating a response of yes and 0 a response of no.

Chi-Square and $t$-test analyses were used to examine the following research questions: (1) Are there differences between the offender, victim, and case characteristics of maternal filicide as compared to paternal filicide? (2) Are there differences in the pre-incarceration negative life events and mental health histories of filicidal women as compared to the two reference groups-filicidal men and women 
were incarcerated for the murder or manslaughter of someone other than their biological or stepchild? The results of these inquiries are presented below.

\section{Results}

As can be seen in Table 1, the mean age for the female filicide group at the time of the interview was approximately 32 years. Almost half $(49 \%)$ were White, non-Hispanic. Only one-fifth of the group was married at the time of the interview. The average level of educational attainment prior to imprisonment was approximately 11 years. The women had a mean number of 2.4 biological, adopted, or stepchildren. A similar mean number of children under the age of 18, including biological, adopted, step, or some other relationship, were living with them prior to arrest $(M=2.5)$. The women were relatively young at the time of the arrest $(M=25.2)$. They had served on average five years with an average sentence length of approximately 35 years (life sentence $=100$ years). Six of the women $(11 \%)$ were serving life sentences. The vast majority of the group had little involvement with the criminal justice system prior to the present offense. Less than $13 \%$ had been on probation previously and even fewer $(7 \%)$ had been incarcerated previously. ${ }^{1}$

Table 1. Descriptive statistics of the women incarcerated for filicide and reference groups.

\begin{tabular}{|c|c|c|c|c|c|}
\hline & Filicidal Men & Filicidal Women & & $\begin{array}{c}\text { Non-Filicidal } \\
\text { Women }\end{array}$ & \\
\hline & $n=28$ & $n=55$ & & $n=333$ & \\
\hline White non-Hispanic & $39.3 \%$ & $49.1 \%$ & & $46.2 \%$ & \\
\hline $95 \% \mathrm{CI}^{\wedge}$ & $23.6-57.6 \%$ & $36.4-61.9 \%$ & & $41.0-51.6 \%$ & \\
\hline Black non-Hispanic & $35.7 \%$ & $30.9 \%$ & & $39.0 \%$ & \\
\hline $95 \%$ CI & $20.7-54.2 \%$ & $20.3-44.0 \%$ & & $34.0-44.4 \%$ & \\
\hline Hispanic & $14.3 \%$ & $14.5 \%$ & & $7.8 \%$ & \\
\hline $95 \% \mathrm{CI}$ & $5.7-31.5 \%$ & $7.6-26.2 \%$ & & $5.4-11.2 \%$ & \\
\hline Other non-Hispanic & $10.7 \%$ & $5.5 \%$ & & $6.9 \%$ & \\
\hline $95 \% \mathrm{CI}$ & $3.7-27.2 \%$ & $1.9-14.9 \%$ & & $4.7-10.2 \%$ & \\
\hline Age (mean) & 41.4 & $31.6^{* * *, * * *}$ & $t(83)=4.3$ & 38.5 & $t(388)=-5.9$ \\
\hline $95 \%$ CI & $37.2-45.6$ & $29.6-33.7$ & & $37.3-39.7$ & \\
\hline Years of education (mean) & 11.7 & 10.8 & & 11.4 & \\
\hline $95 \% \mathrm{CI}$ & $10.4-12.9$ & $10.1-11.6$ & & $11.1-11.7$ & \\
\hline Married & $28.6 \%$ & $20.0 \%$ & & $11.7 \%$ & \\
\hline $95 \% \mathrm{CI}$ & $15.3-47.1 \%$ & $11.6-32.4 \%$ & & $8.7-15.6 \%$ & \\
\hline Number of children (mean) & 3.1 & 2.4 & & 2.1 & \\
\hline $95 \%$ CI & $2.2-4.0$ & $2.0-2.8$ & & $1.9-2.3$ & \\
\hline $\begin{array}{c}\text { Number of children }<18 \\
\text { living with (mean) }\end{array}$ & 1.4 & $2.5^{* * * * * *}$ & $t(76)=-3.0$ & 1.7 & $t(292)=3.3$ \\
\hline $95 \% \mathrm{CI}$ & $0.9-1.9$ & $2.0-2.9$ & & $1.5-1.9$ & \\
\hline Age at arrest (mean) & 33.5 & $25.2^{* * * * * * *}$ & $t(79)=3.7$ & 31.2 & $t(361)=-6.0$ \\
\hline $95 \% \mathrm{CI}$ & $29.2-37.8$ & $23.6-26.8$ & & $30.1-32.4$ & \\
\hline Time served (mean; years) & 7.3 & 5.3 & & 6.3 & \\
\hline $95 \% \mathrm{CI}$ & $5.1-9.4$ & $4.1-6.5$ & & $5.8-6.8$ & \\
\hline $\begin{array}{c}\text { Sentence length } \\
\text { [mean (median); years] }\end{array}$ & $49.5(30.0)$ & $34.6(20.0)$ & & $43.4(25.0)$ & \\
\hline $95 \%$ CI & $31.6-67.4$ & $24.9-44.4$ & & $38.8-48.0$ & \\
\hline Prior probation & $42.9 \%$ & $12.7 \% * * * *$ & $\chi^{2}(1, n=83)=9.5$ & $26.4 \%$ & $\chi^{2}(1, n=388)=4.8$ \\
\hline $95 \% \mathrm{CI}$ & $26.5-60.9 \%$ & $6.3-24.0 \%$ & & $22.0-31.4 \%$ & \\
\hline Prior incarceration & $39.3 \%$ & $7.3 \% * * *$ & $\chi^{2}(1, n=83)=12.8$ & $17.0 \%$ & \\
\hline $95 \% \mathrm{CI}$ & $23.6-57.6 \%$ & $2.9-17.3 \%$ & & $13.3-21.5 \%$ & \\
\hline
\end{tabular}

^upper and lower $95 \%$ confidence intervals. ${ }^{*} p<0.05,{ }^{* *} p<0.01$, and ${ }^{* * *} p<0.001$.

As mentioned above, two reference groups were utilized in the present analysis: filicidal males and non-filicide females. Significant gender differences between the filicidal perpetrators include age, age at arrest, number of children under the age of 18 living with them prior to arrest, prior probation, and prior incarceration. With the exception of prior incarceration, the same measures were found to be significant differences between the two groups of incarcerated women. As such, compared to the reference groups, women incarcerated for filicide were younger at both the time of arrest and at data 
collection, had more children under the age of 18 living with them prior to arrest, and had less prior criminal justice involvement.

Next, we examined offense and victim characteristics to determine if any gender differences existed between filicide perpetrators (Table 2). All of the cases of filicide involved a single victim and little difference was found in the victim's sex. However, significant differences were found for victim-offender relationship, age of victim, and location of offense. Nearly all of the cases with a female offender involved the death of a biological child (95\%) compared to about two-thirds of the cases with a male offender (68\%). Additionally, in all but one case involving a female perpetrator, the victim was 12 years of age or younger $(98 \%)$, while in over a quarter of the male perpetrator cases $(29 \%)$, the victim was above the age of 13 . Among the women, approximately $90 \%$ of the offenses occurred in the home that the victims shared with their (step)mothers. In contrast, only about two-thirds of the offenses committed by men occurred in the home that the victims lived in with their (step)fathers. This difference suggests that fewer victims were living with their fathers at the time of offense, possibly because the victims who were under age of 18 were living primarily with their mothers or other caretakers and the adult victims were living independently. Finally, a higher number of cases with a female perpetrator involved an accomplice (i.e., another individual who was also charged in the offense) as compared to cases with a male perpetrator, $29 \%$ versus $4 \%$.

Table 2. A comparison of victim and offense characteristics in filicide cases.

\begin{tabular}{|c|c|c|c|}
\hline & Filicidal Women & & Filicidal Men \\
\hline & $n=55$ & & $n=28$ \\
\hline Single victim & $100.00 \%$ & & $100.00 \%$ \\
\hline $95 \% \mathrm{CI}^{\wedge}$ & $93.5-100 \%$ & & $87.9-100 \%$ \\
\hline \multicolumn{4}{|l|}{ Victim/offender relationship } \\
\hline Biological child & $94.5 \% * *$ & $\chi^{2}(1, n=83)=10.7$ & $67.9 \%$ \\
\hline $95 \% \mathrm{CI}$ & $85.2-98.1 \%$ & & $49.3-82.1 \%$ \\
\hline Stepchild & $5.4 \%$ & & $32.1 \%$ \\
\hline $95 \% \mathrm{CI}$ & $1.9-14.9 \%$ & & $17.9-50.7 \%$ \\
\hline \multicolumn{4}{|l|}{ Victim's sex } \\
\hline Male & $55.6 \%$ & & $53.6 \%$ \\
\hline $95 \% \mathrm{CI}$ & $42.4-68.0 \%$ & & $35.8-70.5 \%$ \\
\hline Female & $44.4 \%$ & & $46.4 \%$ \\
\hline $95 \% \mathrm{CI}$ & $32.0-57.6 \%$ & & $29.5-64.2 \%$ \\
\hline \multicolumn{4}{|l|}{ Age of victim } \\
\hline$\leq 12$ & $98.1^{* * *}$ & $\chi^{2}(1, n=80)=13.0$ & $71.4 \%$ \\
\hline $9 \overline{5} \% \mathrm{CI}$ & $89.9-99.7 \%$ & & $52.9-84.8 \%$ \\
\hline $13-17$ & 1.9 & & $7.1 \%$ \\
\hline $95 \% \mathrm{CI}$ & $0.03-10.1 \%$ & & $2.0-22.6 \%$ \\
\hline $18-24$ & & & $14.3 \%$ \\
\hline $95 \% \mathrm{CI}$ & & & $5.7-31.5 \%$ \\
\hline $25-34$ & & & $3.6 \%$ \\
\hline $95 \% \mathrm{CI}$ & & & $0.6-17.7 \%$ \\
\hline $35-54$ & & & $3.6 \%$ \\
\hline $95 \%$ CI & & & $0.6-17.7 \%$ \\
\hline \multicolumn{4}{|l|}{ Location of offense } \\
\hline Offender and victim's house & $86.5 \% *$ & $\chi^{2}(1, n=78)=4.8$ & $65.4 \%$ \\
\hline $95 \%$ CI & $74.7-93.3 \%$ & & $46.2-80.6 \%$ \\
\hline Accomplice & $29.1 \%$ & & $3.6 \%$ \\
\hline $95 \%$ CI & $18.8-42.1 \%$ & & $0.6-17.7 \%$ \\
\hline
\end{tabular}

^upper and lower $95 \%$ confidence intervals. ${ }^{*} p<0.05,{ }^{* *} p<0.01$, and ${ }^{* * *} p<0.001$.

Turning to negative life events, approximately $40 \%$ of women incarcerated for filicide reported that had they received public assistance as a child or that their caretakers had an issue with substance abuse (Table 3). Lower percentages were noted for public housing, foster care, and parental incarceration. Similar percentages were noted between the two groups of incarcerated women on the childhood negative life events with one exception: public assistance as a child. About $43 \%$ of filicidal women reported receiving public assistance as a child as compared to $31 \%$ of non-filicidal women. When comparing among filicide perpetrators, a higher percentage of males incarcerated for filicide reported 
living in public housing as a child as compared to females incarcerated for the same offense (26\% versus $15 \%)$. However, greater percentages of women reported parental incarceration and public assistance as a child. None of these differences were statistically significant.

An examination of more recent measures of economic hardship indicates that women incarcerated for filicide were struggling financially. They were twice as likely as their counterparts to report receiving public assistance (e.g., welfare) in the month prior to arrest, and especially compared to the men, they reported a much lower mean monthly income. Both of these measures were statistically significant when compared to the reference groups. Additionally, filicidal women were also the least likely of all three groups to report being employed in the month prior to arrest, a statistically significant difference between them and the filicidal men. One final indicator of economic hardship-homelessness in the year prior to arrest-indicates that higher percentages of women in both groups reported that they were homeless (around 10\%) as compared to approximately four percent of the men.

Table 3. Negative life events of women incarcerated for filicide and reference groups.

\begin{tabular}{|c|c|c|c|c|c|}
\hline & Filicidal Men & Filicidal Women & & $\begin{array}{c}\text { Non-Filicidal } \\
\text { Women }\end{array}$ & \\
\hline & $n=28$ & $n=55$ & & $n=333$ & \\
\hline Caretaker substance abuse & $39.3 \%$ & $40.0 \%$ & & $46.1 \%$ & \\
\hline $95 \% \mathrm{CI}^{\wedge}$ & $23.6-57.6 \%$ & $28.1-53.2 \%$ & & $40.8-51.5 \%$ & \\
\hline Public housing & $25.9 \%$ & $14.5 \%$ & & $13.0 \%$ & \\
\hline $95 \% \mathrm{CI}$ & $13.2-44.7 \%$ & $7.6-26.2 \%$ & & $9.8-17.0 \%$ & \\
\hline Parental incarceration & $14.8 \%$ & $21.8 \%$ & & $21.3 \%$ & \\
\hline $95 \% \mathrm{CI}$ & $5.9-32.5 \%$ & $13.0-34.4 \%$ & & $17.2-26.0 \%$ & \\
\hline Foster care & $14.3 \%$ & $9.4 \%$ & & $11.1 \%$ & \\
\hline $95 \%$ CI & $5.7-31.5 \%$ & $4.1-20.3 \%$ & & $8.1-15.0 \%$ & \\
\hline $\begin{array}{c}\text { Homeless (year prior to } \\
\text { arrest) }\end{array}$ & $3.6 \%$ & $9.1 \%$ & & $9.5 \%$ & \\
\hline $95 \% \mathrm{CI}$ & $0.6-17.7 \%$ & $4.0-19.6 \%$ & & $6.7-13.1 \%$ & \\
\hline Public assistance (child) & $30.8 \%$ & $42.6 \%$ & & $31.3 \%$ & \\
\hline $95 \%$ CI & $16.5-50.0 \%$ & $30.3-55.8 \%$ & & $26.5-36.5 \%$ & \\
\hline Employed ^ & $85.7 \%$ & $54.7 \%$ ** & $\chi^{2}(1, n=83)=7.9$ & $65.2 \%$ & \\
\hline $95 \%$ CI & $56.6-87.3 \%$ & $36.4-61.9 \%$ & & $46.6-57.3 \%$ & \\
\hline Public assistance ${ }^{\wedge}$ & $17.9 \%$ & $40.0 \% * * *$ & $\chi^{2}(1, n=83)=4.2$ & $21.0 \%$ & $\chi^{2}(1, n=384)=9.4$ \\
\hline $95 \% \mathrm{CI}$ & $7.9-35.6 \%$ & $28.1-53.2 \%$ & & $16.9-25.7 \%$ & \\
\hline Monthly income (mean ^^) & $\$ 1200-1499$ & $\$ 600-799 * * *, *$ & $t(71)=4.7$ & $\$ 800-999$ & $t(327)=-2.48$ \\
\hline $95 \% \mathrm{CI}$ & $\$ 800-1999$ & $\$ 400-999$ & & $\$ 600-1199$ & \\
\hline Physical abuse (lifetime) & $28.6 \%$ & $52.7 \% * * *$ & $\chi^{2}(1, n=83)=4.4$ & $70.9 \%$ & $\chi^{2}(1, n=385)=7.2$ \\
\hline $95 \% \mathrm{CI}$ & $15.3-47.1 \%$ & $39.8-65.3 \%$ & & $65.8-75.6 \%$ & \\
\hline Sexual abuse (lifetime) & $3.6 \%$ & $47.3 \% * * *$ & $\chi^{2}(1, n=83)=16.2$ & $58.5 \%$ & \\
\hline $95 \% \mathrm{CI}$ & $0.6-17.7 \%$ & $34.7-60.2 \%$ & & $53.1-63.7 \%$ & \\
\hline
\end{tabular}

^upper and lower $95 \%$ confidence intervals. ${ }^{\wedge}$ month prior to arrest; ${ }^{*} p<0.05,{ }^{* *} p<0.01$, and ${ }^{* * *} p<0.001$.

Abuse was frequently reported by the female filicide perpetrators. About half reported that they had been victims of physical $(52.7 \%)$ or sexual abuse $(47.3 \%)$. These percentages were significantly higher than those of the male reference group, especially for sexual abuse. However, non-filicidal women had higher percentages of both abuses than filicidal women with a significant difference on physical abuse.

The final area of inquiry was mental health history (Table 4). One-half of women incarcerated for filicide indicated that they had a mental/emotional problem, a statistically significant difference between them and the reference groups. When looking at specific disorders from the 2004 survey only, similar percentages were noted between the two groups of female inmates with the exceptions of PTSD and personality disorder. With both measures, a higher percentage of non-filicide women reported receiving a diagnosis as compared to the filicidal women. However, when examining sex differences, much higher percentages were noted for women incarcerated for filicide as compared to their male counterparts on most measures. In fact, as compared to filicidal men, women incarcerated for filicide were significantly more likely to report being diagnosed with a depressive disorder ( $54 \%$ versus $9 \%$ ) and report a significantly higher mean number of mental/emotional problems (1.2 versus 0.4$)$. 
Table 4. Mental health histories of women incarcerated for filicide and reference groups.



Lastly, when reviewing their treatment history, the majority of filicidal women had taken a medication or received counseling for a mental/emotional problem. As indication of potentially more serious mental health issues, over one-third had stayed overnight in a mental health hospital or facility. Compared to the male reference group, the women had much more extensive treatment histories. Twice as many women incarcerated for filicide had taken a mental health medication or received mental health counseling and approximately five times as many women had stayed overnight in a hospital for a mental/emotional problem than their male counterparts. Significant sex differences were found for all three treatment history indicators. Similar percentages were found between the female groups for medication and counseling, though a statistically significant higher percentage of filicidal women had stayed overnight in hospital for a mental/emotional issue.

\section{Discussion}

Despite the gravity of the crime committed, there is little empirical research on maternal filicide, especially involving relatively large samples, national level data, and using multiple comparison groups. As such, the purpose of this study was to fill some of the gaps in understanding by focusing on the victim and offense characteristics, negative life events, and mental health histories of filicidal women as compared to filicidal men and for non-filicidal women. The results of this study reveal important differences between the population of interest and the two reference groups. After comparing victim and offense characteristics for those incarcerated for filicide, several gender differences were noted, which suggest meaningful differences in the situational characteristics of these crimes. As compared to cases involving male offenders, cases involving female offenders were significantly more likely to occur in a home cohabitated by the offender and the victim and to involve a younger victim who was the offender's biological child. Since all but 1 of the 55 cases with a female perpetrator involved the death of her biological child, these findings are supportive of previous studies 
that dispel the "wicked stepmother" myth (Alder and Polk 2001; Harris et al. 2007). Additionally, consistent with previous research (Alder and Polk 2001; Harris et al. 2007), a sizeable number of cases with a male offender involved a stepchild. Consequently, connections can be drawn to biological theories, which posit that men would be less likely to kill their genetic heirs (Alder and Polk 2001; Daly and Wilson 1988).

The examination into the pre-incarceration negative life events revealed significant differences in the abuse histories and recent economic hardship between filicidal women and the two reference groups. As compared to men incarcerated for the same offense, filicidal women were significantly more likely to report being the victims of physical or sexual abuse. These results are consistent with previous research that noted the high prevalence of abuse among incarcerated women (Leigey and Reed 2010; Oberman and Meyer 2008). While reports of lifetime prevalence of physical abuse for filicidal women are very similar to estimates for the general population of women-about 51.9\% (Tjaden and Thoennes 2000), reported that rates of sexual abuse are much higher than estimates derived from general population studies (National Research Council 2014). However, it is important to note that non-filicidal women had higher percentages of both abuses, and significantly higher for physical abuse, than filicidal women. Thus, in this study, abuse was not a negative life event that distinguished women incarcerated for filicide from women who were incarcerated for other types of murder or manslaughter.

However, recent economic deprivation was a negative prior experience that separated women incarcerated for filicide from the two reference groups. Economic measures in the month prior to the offense indicate that filicidal women had faced greater financial struggles than either reference group. As compared to the two reference groups, filicidal women were significantly more likely to report receiving public assistance and indicated a lower mean monthly income. Moreover, they were significantly less likely to report being employed than their male counterparts. These findings are consistent with the extant literature, which has noted that financial pressures are an important factor in maternal filicide cases (Alder and Polk 2001; Hatters Friedman and Resnick 2007; Scott and Fleming 2014). For example, Oberman and Meyer (2008) in their study of eight women incarcerated for filicide found: "The majority had not finished secondary school; they had little means of supporting themselves and were dependent on the good will of others for housing, food, and support" (p. 68). Importantly, estimates of recent economic deprivation for filicidal mothers are higher than for mothers in the general population. Data from U.S. Bureau of Labor Statistics indicate that, during the 1990s, between 67.2-73\% of mothers with minor children were employed (U.S. Department of Labor 2008). According to data from the U.S. Census Bureau, about $21.7 \%$ of mothers were on public assistance in 2004 , including $34.2 \%$ of mothers who had a child in the last year (Dye 2008).

The final phase of the analysis was to examine mental health history. About half of filicidal women reported a mental/emotional problem, a significantly higher percentage than either reference group. Notably, data from the National Institute of Mental Health indicates that about 21.7\% of women in the general population have some mental health issue (National Institute of Mental Health 2017). Comparatively, half of the filicidal women in the current study reported having a mental health problem. This finding is supportive of previous research that found that women who commit filicide were more likely to have a mental disorder than their male counterparts (Flynn et al. 2013; Palermo 2002). While maternal filicide is commonly attributed to severe mental illness (Alder and Polk 2001; Barnett 2006; Flynn et al. 2013), the fact that half of the women did not report a mental/emotional problem is notable and consistent with previous studies (Alder and Polk 2001; Holland et al. 2015; Porter and Gavin 2010; Stroud 2008). This finding could reflect the fact that offenders with serious illness may be confined in mental institutions and not prisons, and as a result be excluded from the sample. Alternatively, the finding could reflect the fact that mental illness is a contributing factor in some but not all cases of maternal filicide. The 2004 data, in which more specific measures were included, indicated that women incarcerated for filicide were significantly more likely to report being diagnosed with a depressive disorder and to report a higher mean number of problems than 
their male counterparts. Although the proportion of filicidal women reporting a suicide attempt was double that of filicidal men, the difference was not statistically significant.

Additionally, women who killed their child had more extensive treatment histories than the filicidal men as they were significantly more likely to report taking a medication, receiving counseling, or staying in a hospital overnight for a mental/emotional problem. Two explanations for these findings can be offered. The first is that filicidal women have greater mental health issues than men incarcerated for the same offense. However, an alternate explanation is that women are more likely to seek treatment for mental health issues than men (Young 2015). While similar percentages of women in both groups reported taking a medication and receiving counseling, filicidal women were significantly more likely to report an overnight stay in a hospital for a mental/emotional problem than the female reference group.

Several important limitations to this study must be noted. First, the data used for this study are now between 14 to 21 years old. The current generation of parents might have had different childhood experiences than the participants of this study. For example, research indicates that the rates of childhood sexual abuse have been declining since the 1990s (Finkelhor and Jones 2012). Second, findings were based on a sample of incarcerated offenders that is relatively small compared to the total number of filicides that take place every year. According to the Supplementary Homicide Reports data for the years 1990-2004, a total of 2976 maternal filicides were reported in that 15-year period. In addition, this study was unable to include cases of murder-suicide (Alder and Polk 2001; Holland et al. 2015) or cases in which the offender is confined in a mental institution. Moreover, important differences could exist in cases of maternal filicide that ended at an earlier point in the criminal justice process, for example, charges were not filed or convictions were not obtained as compared to cases in which offenders were ultimately imprisoned (Scott and Fleming 2014). Third, because of how data on the age of the victim were collected, this study was unable to examine neonaticide or infanticide. Meaningful differences could exist in the offender, victim, and offense characteristics based on this measure (Beyer et al. 2008; Porter and Gavin 2010; Scott and Fleming 2014). Fourth, data were based on the self-reporting of the respondents; as such, underreporting must be acknowledged, in particular in the subject areas in which a stigma exist, for example, abuse and mental health.

While society can be quick to label filicidal women as abhorrent, this research provides insight into the negative life events they experienced over the life course. Before they were offenders, many were victims and many were economically disadvantaged. In addition, while the trauma they suffered does not excuse their behavior, it does offer important context in which their behavior should be regarded. Prevention and early intervention are two important policy recommendations derived from this study. The importance of mental health service cannot be understated. Counseling is necessary to interrupt the pathway of victim of violence to perpetrator. Additionally, parenting programs that provide a safe space for mothers and fathers to discuss the challenges and frustrations that accompany parenthood and teach them skills to cope with its demands would be valuable. As economic marginalization was commonly noted among the filicidal women, access to programs that are designed to ease financial burdens are recommended, for example, vocational and educational training. Program directors should be mindful of their maternal status and provide opportunities to increase participation and engagement such as transportation and childcare.

Author Contributions: Conceptualization, M.P. and M.L.; methodology, M.L.; formal analysis, M.L.; writing_original draft preparation, M.P. and M.L.; writing—review and editing, M.P. and M.L.

Funding: This research received no external funding.

Conflicts of Interest: The authors declare no conflict of interest. 


\section{References}

Alder, Catherine, and Kenneth Polk. 2001. Child Victims of Homicide. New York: Cambridge University Press. Amon, Sabine, Hanna Putkonen, Ghitta Weizmann-Henelius, P. Fernandez Arias, and Claudia M. Klier. 2018. Gender Differences in Legal Outcomes of Filicide in Austria and Finland. Archives of Women's Mental Health. Available online: https:/ /link.springer.com/article/10.1007/s00737-018-0867-5 (accessed on 18 September 2018).

Barnett, Barbara. 2006. Medea in the Media. Journalism 7: 411-32. [CrossRef]

Benitez-Borrego, Sonia, Joan Guardia-Olmos, and Alvaro Aliaga-Moore. 2013. Child Homicide by Parents in Chile: A Gender-Based Study and Analysis of Post-Filicide Attempted Suicide. International Journal of Law and Psychiatry 36: 55-64. [CrossRef] [PubMed]

Beyer, Kristen, Shannon M. Mack, and Joy L. Shelton. 2008. Investigative Analysis of Neonaticide: An Exploratory Study. Criminal Justice and Behavior 35: 522-35. [CrossRef]

Bourget, Dominique, and Pierre Gagne. 2002. Maternal Filicide in Quebec. Journal of American Academy of Psychiatry \& the Law 30: 345-51.

Bourget, Dominique, Jennifer Grace, and Laurie Whitehurst. 2007. A Review of Maternal and Paternal Filicide. The Journal of the American Academy of Psychiatry and the Law 35: 74-82. [PubMed]

Bureau of Justice Statistics. 1997. Survey of inmates in state and federal correctional facilities, 1997. Available online: https:/ / www.icpsr.umich.edu/icpsrweb/ICPSR/series/70 (accessed on 18 September 2018).

Bureau of Justice Statistics. 2004. Survey of Inmates in State and Federal Correctional Facilities, 2004. Available online: https:/ / www.icpsr.umich.edu/icpsrweb/ICPSR/series/70 (accessed on 18 September 2018).

Crimmins, Susan, Sandra Langley, Henry H. Brownstein, and Barry J. Spunt. 1997. Convicted Women who have Killed Children: A Self-Psychology Perspective. Journal of Interpersonal Violence 12: 49-69. [CrossRef]

D'Orban, P. T. 1979. Women who Kill Their Children. British Journal of Psychology 134: 560-71. [CrossRef]

Daly, Martin, and Margo Wilson. 1988. Evolutionary Social Psychology and Family Homicide. Science 242: 519-24. [CrossRef] [PubMed]

Debowska, Agata, Daniel Boduszek, and Katie Dhingra. 2015. Victim, Perpetrator, and Offense Characteristics in Filicide and Filicide-Suicide. Aggression and Violent Behavior 21: 113-24. [CrossRef]

Dixon, Shane, Jessie L. Krienert, and Jeffrey Walsh. 2014. Filicide: A Gendered Profile of Offender, Victim, and Event Characteristics in a National Sample of Reported Incidents, 1995-2009. Journal of Crime and Justice 37: 339-55. [CrossRef]

Dye, Jane Lawler. 2008. Participation of Mothers in Government Assistance Programs: 2004; Washington: U.S. Census Bureau. Available online: https://www.census.gov/prod/2008pubs/p70-116.pdf (accessed on 18 September 2018).

Edalati, Hanie, and Marvin D. Krank. 2016. Childhood Maltreatment and Development of Substance Use Disorders: A Review and a Model of Cognitive Pathways. Trauma, Violence, and Abuse 17: 453-67. [CrossRef] [PubMed]

Eriksson, Li, Paul Mazerolle, Richard Wortley, and Holly Johnson. 2016. Maternal and Paternal Filicide: Case Studies from the Australian Homicide Project. Child Abuse Review 25: 17-30. [CrossRef]

Finkelhor, David, and Lisa Jones. 2012. Have Sexual Abuse and Physical Abuse Declined Since the 1990s? Crimes Against Children Research Center Fact Sheet. Available online: http:/ / unh.edu/ccrc/pdf/CV267_Have\% 20SA\%20\%20PA\%20Decline_FACT\%20SHEET_11-7-12.pdf (accessed on 18 September 2018).

Flynn, Sandra M., Jenny J. Shaw, and Kathryn M. Abel. 2013. Filicide: Mental Illness in Those who Kill their Children. PLOS ONE 8: e58981. Available online: http://journals.plos.org/plosone/article?id=10.1371/ journal.pone.0058981 (accessed on 18 September 2018).

Fox, James Alan, and Emma E. Fridel. 2017. Gender Differences in Patterns and Trends in U.S. Homicide, 1976-2015. Violence and Gender 4: 37-43. [CrossRef]

Haapsalo, Jaana, and Sonja Petaja. 1999. Mothers who Killed or Attempted to Kill their Children: Life Circumstances, Childhood Abuse, and Types of Killing. Violence and Victims 14: 219-39. [CrossRef]

Harris, Grant T., Zoe N. Hilton, Marnie E. Rice, and Angela W. Eke. 2007. Children Killed by Genetic Parents versus Stepparents. Evolution and Human Behavior 28: 85-95. [CrossRef]

Hatters Friedman, Susan, and Philip J. Resnick. 2007. Child Murder by Mothers. World Psychiatry: Official Journal of the World Psychiatric Association (WPA) 6: 137-41. 
Hatters Friedman, Susan, Sarah McCue Horwitz, and Philip. J. Resnick. 2005. Child Murder by Mothers: A Critical Analysis of the Current State of Knowledge and a Research Agenda. American Journal of Psychiatry 162: 1578-87. [CrossRef] [PubMed]

Holland, Kristin M., Sabrina V. Brown, Jeffrey E. Hall, and Joseph E. Logan. 2015. Circumstances Preceding Homicide-Suicide Involving Child Victims: A Qualitative Analysis. Journal of Interpersonal Violence 33: 379-401. [CrossRef] [PubMed]

Jewkes, Yvonne. 2015. Media and Crime, 3rd ed. Thousand Oaks: SAGE.

Kauppi, Anne, Kirsti Kumpulainen, Kari Karkola, Tuija Vanamo, and Juhani Merikanto. 2010. Maternal and Paternal Filicides: A Retrospective Review of Filicides in Finland. Journal of the American Academy of Psychiatry and Law 38: 229-38.

Krischer, Maya K., Michael H. Stone, Kathrin Seveke, and Eckhard M. Steinmeyer. 2007. Motives for Maternal Filicide: Results from a Study with Female Forensic Patients. International Journal of Law and Psychiatry 30: 191-200. [CrossRef] [PubMed]

Leigey, Margaret E., and Katie L. Reed. 2010. A Woman's Life Before Serving Life: Examining the Negative Pre-Incarceration Life Events of Female Life-Sentenced Inmates. Women \& Criminal Justice 20: 302-22.

Leveillee, Suzanne, Jacques D. Marleau, and Myriam Dube. 2007. Filicide: A Comparison by Sex and Presence or Absence of Self-Destructive Behavior. Journal of Family Violence 22: 287-95. [CrossRef]

Lewis, Catherine F., and Scott C. Bunce. 2003. Filicidal Mothers and the Impact of Psychosis on Maternal Filicide. Journal of the American Academy of Psychiatry \& the Law 31: 459-70.

Liem, Marieke, and Frans Koenraadt. 2008. Filicide: A Comparative Study of Maternal versus Paternal Child Homicide. Criminal Behavior and Mental Health 18: 166-76. [CrossRef] [PubMed]

Lysell, Henrik, Bo Runenson, Paul Lichtenstein, and Niklas Langstrom. 2014. Risk Factors for Filicide and Homicide: 36-year National Matched Cohort Study. Journal of Clinical Psychiatry 75: 127-32. [CrossRef] [PubMed]

Mariano, Timothy Y., Heng Choon (Oliver) Chan, and Wade C. Myers. 2014. Toward a More Holistic Understanding of Filicide: A Multidisciplinary Analysis of 32 years of U.S. Arrest Data". Forensic Science International 236: 46-53. [CrossRef] [PubMed]

McKee, Geoffrey R., and Steven J. Shea. 1996. Homicidal Women: Characteristics of Filicide, Spouse, and Non-Family Murder Defendants. Paper presented at the meeting of the American Psychological Association, Toronto, ON, Canada, August 9.

Mckee, Geoffrey R., and Steven J. Shea. 1998. Maternal Filicide: A Cross-National Comparison. Journal of Clinical Psychology 54: 679-87. [CrossRef]

McKee, Geoffrey R., Steven J. Shea, Robert B. Mogy, and Carol E. Holden. 2001. MMPI-2 Profiles of Filicidal, Mariticidal, and Homicidal Women. Journal of Clinical Psychology 57: 367-74. [CrossRef] [PubMed]

Mugavin, Marie. E. 2005. A Meta-Synthesis of Filicide Classification Systems: Psychosocial and Psychodynamic Issues in Women who Kill Their Children. Forensic Nursing 1: 65-72. [CrossRef] [PubMed]

National Institute of Mental Health. 2017. Statistics. Available online: https://www.nimh.nih.gov/health/ statistics/mental-illness.shtml (accessed on 18 September 2018).

National Research Council. 2014. Estimating the Incidence of Rape and Sexual Assault. Washington: The National Academies Press.

Oberman, Michelle, and Cheryl L. Meyer. 2008. When Mothers Kill: Interviews from Prison. New York: New York University Press.

Palermo, George B. 2002. Murderous Parents. International Journal of Offender Therapy and Comparative Criminology 46: 123-43. [CrossRef] [PubMed]

Porter, Theresa, and Helen Gavin. 2010. Infanticide and Neonaticide: A Review of 40 years of Research Literature on Incidence and Causes. Trauma, Violence, E Abuse 11: 99-112.

Putkonen, Hannah, Ghitta Weizmann-Henelius, Nina Lindberg, Markku Eronen, and Helina Hakkanen. 2009. Differences Between Homicide and Filicide Offenders: Results of a Nationwide Register-Based Case-Control Study. BMC Psychiatry 9: 27. [CrossRef] [PubMed]

Putkonen, Hanna, Sabine Amon, Markku Eronen, Claudia M. Klier, Maria P. Almiron, Jenny Yourstone Cederwall, and Ghitta Weizmann-Henelius. 2011. Gender Differences in Filicide Offense Characteristics-A Comprehensive Register-Based Study of Child Murder in Two European Countries. Child Abuse and Neglect 35: 319-28. [CrossRef] [PubMed] 
Putkonen, Hanna, Sabine Amon, Ghitta Weizmann-Henelius, Maiju Pankakoski, Markku Eronen, Maria P. Almiron, and Claudia M. Klier. 2016. Classifying Filicide. International Journal of Forensic Mental Health 15: 198-210. [CrossRef]

Resnick, Philip J. 1969. Child Murder by Parents: A Psychiatric Review of Filicide. American Journal of Psychiatry 126: 73-82. [CrossRef] [PubMed]

Scott, Hannah, and Katie Fleming. 2014. The Female Family Annihilator: An Exploratory Study. Homicide Studies 18: 59-82. [CrossRef]

Sidebotham, Peter. 2013. Rethinking Filicide. Child Abuse Review 22: 305-10. [CrossRef]

Sidebotham, Peter, and Ameeta Retzer. 2018. Maternal Filicide in a Cohort of English Serious Case Reviews. Archives of Women's Mental Health. Available online: https:/ /link.springer.com/article/10.1007/s00737-0180820-7 (accessed on 18 September 2018).

Smithey, Martha. 1997. Infant Homicide at the Hands of Mothers: Toward a Sociological Perspective. Deviant Behavior 18: 255-72. [CrossRef]

Spinelli, Margaret G. 2003. Infanticide: Psychosocial and Legal Perspectives on Mothers Who Kill. Washington: American Psychiatric Publishing Inc.

Stroud, Julia. 2008. A Psychosocial Analysis of Child Homicide. Critical Social Policy 28: 482-505. [CrossRef]

Tjaden, Patricia, and Nancy Thoennes. 2000. Full Report of the Prevalence, Incidence, and Consequences of Violence Against Women: Findings from the National Violence Against Women Survey. Washington: National Institute of Justice. Available online: https:/ / www.ncjrs.gov / pdffiles1/nij/183781.pdf (accessed on 18 September 2018).

U.S. Department of Labor. 2008. Women in the Labor Force: A Databook. Available online: https://www.bls.gov/ cps/wlf-databook-2008.pdf (accessed on 18 September 2018).

Vanamo, Tuija, Anne Kauppi, Kari Kankola, Juhani Merikanto, and Eila Räsänen. 2001. Intra-Familial Child Homicide in Finland 1970-1994: Incidence, Causes of Death and Demographic Characteristics. Forensic Science International 17: 199-204. [CrossRef]

Weekes-Shackelford, Viviana A., and Todd K. Shackelford. 2004. Methods of Filicide: Stepparents and Parents Kill Differently. Violence and Victims 19: 75-81. [CrossRef] [PubMed]

Wilbanks, William. 1983. Female Homicide Offenders in the U.S. International Journal of Women Studies 6: 302-10. Wilczynski, Anna. 1997. Child Homicide. London: Greenwich Medical Media Ltd.

Wilson, Margo, Martin Daly, and Antonletta Daniele. 1995. Familicide: The Killing of Spouse and Children. Aggressive Behavior 21: 275-91. [CrossRef]

Young, Joel L. 2015. Women and Mental Illness. Psychology Today, April 22. Available online: https://www.psychologytoday.com/blog/when-your-adult-child-breaks-your-heart/201504/ women-and-mental-illness (accessed on 18 September 2018). 